\title{
Prevalence of Rotavirus Infection among Diarrheal Children in Baghdad City
}

\author{
Rawaa Abdulkhaleq Hussein ${ }^{1}$, Areej Abd Al-Abbas ${ }^{2}$, Arwa Mujahid Abdullah ${ }^{3}$, Nada Taha Al-Bashier ${ }^{4}$ \\ ${ }^{1}$ Department of Microbiology/College of Medicine/ University of Diyala \\ ${ }^{2}$ Department of pediatric/College of Medicine/ Al-Nahrain University \\ ${ }^{3}$ Department of Microbiology/College of Medicine/Al-Nahrain University \\ ${ }^{4}$ Medical Research Unit/ College of Medicine/ Al-Nahrain University
}

\begin{abstract}
Background: Rotavirus infection causing gastroenteritis is one of the major health concerns throughout the world. Millions of children are affected by the disease. Objectives: To determine the prevalence of Rota virus among diarrheal children and study the relation of Rotavirus with some of the major socio- demographic factors and clinical features. Materials and Methods: The patients of this study included 100 who came to the AL-Imamin AL-Kadhimin Medical City, suffering from gastrointestinal complaints with diarrhea. General fecal samples were taken from them during the period from May 2014 to February 2015. The age range was 1 month to 18 years. The fecal specimens were collected in sterile containers, stored at -20c until test for the presence of human Rotavirus antigen by ELISA and Dia spot test were performed. Results: We examined 100 children with diarrhea; the rotavirus antigen was detected in $24 \%$ of fecal specimens from children with diarrhoea. Human rotavirus antigen was detected more in stool of child less than 2 years of age, more in low mother education group and rural patients; and less among breast-fed infants. There was no sex predilection to get the infection with the virus. Children with diarrhoea due to rotavirus infection may have certain clinical features that raise the indexes of suspicion for a clinical diagnosis of the condition. Conclusion: The present study confirms the current burden of rotavirus gastroenteritis in infants, and usually associated with one or more respiratory symptoms and it is highly prevalent among children from rural areas and of low mother education. The clinical features from children with rotavirus gastroenteritis are non-specific but highly suggestive and should raise the indexes of suspicion of infection with this virus.
\end{abstract}

Keywords: Rotavirus, diarrheal children and clinical features

\section{Introduction}

The World Health Organization (WHO) ranks diarrheal disease as the second most common cause of morbidity and mortality in children in the developing world (1), where poor sanitary and hygienic conditions exist. More than 5000 children are dying every day as a result of diarrheal disease.

Many studies have been conducted in various geographic sites to identify the etiology of these diarrheal illnesses and to formulate a composite picture for estimating their global burden. The etiological agents of diarrhea include viruses, bacteria, and parasites. The incidence of pathogens causing diarrhea varies between developed and developing countries. In developed countries about $70 \%$ of diarrheal cases are of viral $(40 \%$ rotavirus $)(2)$, while $35 \%$ viral incidence $(15 \%$ $25 \%$ rotavirus)in developing countries(3). Rotaviruses comprise a genus within the family Reoviridae. Therotavirion has a non enveloped, complex, triple-layered capsid structure that surrounds a genome composed of 11 segments of double-stranded RNA. There are six structural proteins and six nonstructural proteins, each encoded in aunique genome segment except for nonstructural proteins 5 and 6 (NSP5 andNSP6), which are encoded in overlapping reading frames of a single segment. Therotavirus genus is divided into serological groups from $\mathrm{A}$ to $\mathrm{H}$ have been recognized as infecting various species (4).However, only groups A-C and $\mathrm{H}$ can infect humans, group A viruses being responsible for over $90 \%$ of all infections (5), and has been established as the predominant group causing human rotavirus diarrheal disease . Group B seems to be limited to causing epidemic infection in Asia and the Indian subcontinent, whereas group $\mathrm{C}$ rotavirus causes endemic infections that frequently go unrecognized (6).

Rotaviruses are recognized as the single most significant cause of severe gastroenteritis, malnutrition and diarrhea in young children in both developed and developing countries worldwide (7). Although rotavirus can infect older children and adults, diarrheal disease is primarily observed in children under 2 years of age (7). It has been estimated that worldwide, each year, diarrhea attributable to rotavirus infection results in 453000 deaths in children younger than 5 years which accounts for $37 \%$ of deaths attributable to diarrhoea and $5 \%$ of all deaths in this age group . $90 \%$ of these deaths occur in sub-Saharan Africa and South East Asia(8). The main symptoms of rotavirus gastroenteritis (RVGE) are fever, abdominal pain, lethargy, diarrhea and vomiting that may lead to hypovolemic shock and dehydration (9). Severe cases may lead to death (10).It is not possible to diagnose rotavirus infection by clinical presentation because the clinical features of rotavirus gastroenteritis do not differ from those of gastroenteritis caused by other pathogens. Specific diagnosis of infection with rotavirus is made by finding the virus in the child's stool byenzyme immunoassay. Other methods, such as electron microscopy and PCR, are used in research laboratories to avoid inappropriate use of antimicrobial therapy.

The present study was conducted to assess the prevalence of rota virus among diarrheal children and to investigate the link between rotavirus infection and some of the major 


\section{International Journal of Science and Research (IJSR) \\ ISSN (Online): 2319-7064 \\ Index Copernicus Value (2013): 6.14 | Impact Factor (2014): 5.611}

socio-demographic factors and clinical features. This could then contribute to appropriate policies aimed at controlling diarrheal diseases.

\section{Materials and Methods}

The patients of this study included 100 who came to the ALImamin AL-Kadhimin Medical City, suffering from gastrointestinal complaints with diarrhea.

General fecal samples were taken from them during the period from May 2014 to February 2015. The age range was 1 month to 18 years.

The fecal specimens were collected in sterile containers, stored at $-20 \mathrm{c}$ until test for the presence of human Rotavirus antigen by ELISA and Dia spot test were performed.

\section{Detection of rotavirus by Dia Spot test}

The one step Rotavirus Rapid Test Device (Acon, Germany) is a rapid visual chromatographic immunoassay for the qualitative detection of rotavirus in human fecal specimens. This kit is intended to be used as an aid in the diagnosis of rotavirus infection. This test was performed according to the manufacturer's specifications.

\section{ELISA test for human Rotavirus Antigen}

The Rotavirus Antigen Detection ELISA kit (RIDASCREEN $®$ Rotavirus test. Germany) is a qualitative determination of rotavirus antigen in feces. This test was performed according to the manufacturer's specifications.

Medical history was recorded and physical examination was carried out for each patient. The following information was recorded: age, sex, residence, date of admission, type of feeding, socioeconomic status and clinical presentation. The study was approved by the ethical committee of the College of Medicine/ Al-Nahrain University.

\section{Statistical Analysis}

Prevalence of infection was compared between different variables by Chi-squared test. Significance was attributed to probability values $\mathrm{P} \leq 0.05$. Computer SPSS and Microsoft excel programs were used for determination of probability values.

\section{Results}

Positive rotavirus antigen was detected in 24 out of 100 samples $(24 \%)$ by DiaSpot and ELISA (Table1). Results of rotavirus detection by Dia Spot test reflecting a sensitivity and specificity of $100 \%, 100 \%$, respectively, the comparisons were made on the assumption that the specimens tested with ELISA were genuinely positive or negative.

Table 1: Comparison of the Rotavirus Results Obtained by Enzyme linked Immuno sorbent assay and Dia Spot test

\begin{tabular}{|c|c|c|c|c|c|}
\hline Methods & $\begin{array}{c}\text { Examined } \\
\text { no. }\end{array}$ & Positive & Negative & Sensitivity & Specificity \\
\hline Diaspot & 100 & 24 & 76 & $100 \%$ & $100 \%$ \\
\hline ELISA & 100 & 24 & 76 & & \\
\hline
\end{tabular}

Of the total rotavirus positive patients, $26.32 \%$ were male and $20.93 \%$ were female, the result showed there was no gender significant preference to get the infection with the virus. The majority of rotavirus-positive cases were observed in children less than 2yearswere 9.5 times likely to have RV $(95 \%$ CI: 1.402-64.38, $\mathrm{p}<0.001)$ than other age groups. Whereas age group of 6-11 years old revealing the lower percent of rotavirus infectivity (7.69\%).Statistically, the frequency of rotavirus infection varied significantly with age groups as shown in table 2 .

The high prevalence of RV was demonstrated in children from rural areas $14(50 \%)$ and $18(38.29 \%)$ their mother have illiterate or in complete primary school. In this study the most child feeding on artificial milk were infected with rotavirus $(85.71 \%)$.

Table 2: Distribution of Rotavirus patients according to gender, age, residence, mother education and type of feeding in the

\begin{tabular}{|c|c|c|c|c|c|c|c|}
\hline \multirow{3}{*}{\multicolumn{2}{|c|}{ Variable Factors }} & \multicolumn{6}{|c|}{ present study } \\
\hline & & \multicolumn{4}{|c|}{ Prevalence of Rota } & \multirow{2}{*}{ Total } & \multirow{2}{*}{$p$ value } \\
\hline & & Positive & $\%$ & Negative & $\%$ & & \\
\hline \multirow{2}{*}{ Gender type } & Female & 9 & 20.93 & 34 & 79.10 & 43 & \multirow{2}{*}{$0.39 \mathrm{NS}$} \\
\hline & Male & 15 & 26.32 & 42 & 73.70 & 57 & \\
\hline \multirow{4}{*}{ Age groups } & $<2$ years & 5 & 50.00 & 5 & 50.00 & 10 & \multirow{4}{*}{$<0.001 *$} \\
\hline & 2-5 years & 14 & 46.67 & 16 & 53.30 & 30 & \\
\hline & 6-11 years & 3 & 7.69 & 36 & 92.30 & 39 & \\
\hline & $12-18$ years & 2 & 9.52 & 19 & 90.50 & 21 & \\
\hline \multirow{2}{*}{ Residence } & Rural & 14 & 50.00 & 14 & 50.00 & 28 & \multirow{2}{*}{$<0.001^{*}$} \\
\hline & Urban & 10 & 13.89 & 62 & 86.11 & 72 & \\
\hline \multirow{3}{*}{$\begin{array}{l}\text { Mother } \\
\text { education }\end{array}$} & Illiterate or in complete primary & 18 & 38.29 & 29 & 61.70 & 47 & \multirow{3}{*}{$0.004 *$} \\
\hline & Primary or secondary & 5 & 15.15 & 28 & 84.84 & 33 & \\
\hline & high school or University & 1 & 5.00 & 19 & 95.00 & 20 & \\
\hline \multirow{2}{*}{$\begin{array}{l}\text { Type of feeding } \\
\text { (1\&2 years) }\end{array}$} & Breast & 1 & 12.50 & 7 & 87.50 & 8 & \multirow{2}{*}{$0.004 *$} \\
\hline & Artificial & 6 & 85.71 & 1 & 14.29 & 7 & \\
\hline
\end{tabular}

p: probability

*Significant $(\mathbf{p} \leq \mathbf{0 . 0 5})$; NS not significant 


\section{International Journal of Science and Research (IJSR) \\ ISSN (Online): 2319-7064 \\ Index Copernicus Value (2013): 6.14 | Impact Factor (2014): 5.611}

Regarding to the clinical presentation (Table.3);57.14\% of child with less than 3 days duration of diarrhea and $51.85 \%$ of patients with RV presented with vomiting as well as, $7.41 \%$ were afebrile and $54.55 \%$ had a low grade fever $(\leq 39$ ${ }^{\circ} \mathrm{C}$ ), dehydration was evident in $85 \%$.
The prevalence of one or more associated respiratory symptoms (nasal discharge, cough, and wheeze) in patients with RV was $88.24 \%$ compared to $89.16 \%$ of patients with non- RV whom never had any respiratory symptom. However all tested child without RV vaccine

Table 3: Distribution of Rotavirus patients according to Clinical features in the present study

\begin{tabular}{|c|c|c|c|c|c|c|c|}
\hline \multirow{2}{*}{\multicolumn{2}{|c|}{ Clinical features }} & \multicolumn{4}{|c|}{ Prevalence of Rota } & \multirow{4}{*}{\begin{tabular}{|c|} 
Total \\
14 \\
86 \\
\end{tabular}} & \multirow{4}{*}{\begin{tabular}{|c}
$p$ value \\
$<0.001^{*}$
\end{tabular}} \\
\hline & & Positive & $\%$ & negative & $\%$ & & \\
\hline \multirow{2}{*}{$\begin{array}{c}\text { Duration of } \\
\text { diarrhea }\end{array}$} & $<3$ & 8 & 57.14 & 6 & 42.86 & & \\
\hline & $>3$ & 16 & 18.60 & 70 & 81.40 & & \\
\hline \multirow{2}{*}{ Vomiting } & Yes & 14 & 51.85 & 13 & 48.15 & 27 & \multirow{2}{*}{$<0.001^{*}$} \\
\hline & non & 10 & 13.70 & 63 & 86.30 & 73 & \\
\hline \multirow{3}{*}{ Fever } & None & 2 & 7.41 & 25 & 92.59 & 27 & \multirow{3}{*}{$<0.001^{*}$} \\
\hline & $\leq 39$ & 18 & 54.55 & 15 & 45.45 & 33 & \\
\hline & $>39$ & 4 & 10.00 & 36 & 90.00 & 40 & \\
\hline \multirow{2}{*}{ Dehydration } & Yes & 17 & 85.00 & 3 & 15.00 & 20 & \multirow{2}{*}{$<0.001 *$} \\
\hline & None & 7 & 8.75 & 73 & 91.25 & 80 & \\
\hline \multirow{2}{*}{$\begin{array}{l}\text { Respiratory } \\
\text { symptoms }\end{array}$} & Yes & 15 & 88.24 & 2 & 11.76 & 17 & \multirow{2}{*}{$<0.001 *$} \\
\hline & None & 9 & 10.84 & 74 & 89.16 & 83 & \\
\hline
\end{tabular}

*Significant ( $p$ value $\leq \mathbf{0 . 0 5})$

\section{Discussion}

Rotavirus is endemic worldwide; the infection is associated with high rates of morbidity throughout the world and high rates of mortality in developing countries (11).

The routine diagnosis of rotavirus is based on rapid detection of group A antigen in faeces, generally by latex agglutination or enzyme immunoassay (12). In this study, viral antigens were determined by immunochromtochraphy and ELISA in 24 (24\%) of 100 stool specimens. However, immunochromtochraphy test was established that (100\%) sensitivity and specificity by detecting of rotavirus with ELISA assays.

The rapid diagnosis of rotavirus infection in patients admitted to the hospital with symptoms of gastroenteritis would enable better treatment of the patient, such as isolation or discharge, as in many cases effective rehydration can be achieved at home, and most rotavirus infections are self-limiting (13). An accurate diagnosis of rotavirus is essential since it obviates the unnecessary use of antibiotic therapy. The methods of choice for the detection of rotavirus in stool samples should have high degrees of sensitivity and specificity, high predictive values, and reproducibility, which ensure consistency of performance in the laboratory.

ELISA test kits for detection of viral antigens is the method commonly used in many laboratories in combination with either electrophero type determination by PAGE or detection of viral particles by electron microscopy, as well as other conventional methods used for detection of viruses (14). The present study demonstrated that the degree of sensitivity and specificity of immunochromtochraphy test showed a roughly linear relationship with the degree of ELISA sensitivity and specificity, Thus, the simple and inexpensive immunochromtochraphy test would be useful as a screening procedure to detect rotaviruses in stools of children with diarrhea.
The prevalence of rotavirus in our study are consistent with other studies about decline in hospital admission. In USA a nationwide study performed by Tate et al showed decline by 67-69\% (15), and in Australia by Buttery et al 2011 showed a reduction by $87 \%$ (16). Occurrence, other studies showed burden of rotavirus gastroenteritis was estimated with high rate in different studies. At 2013, AL- Khafaji et al. In Babil showed positive rotavirus antigen was detected in 108out of 236 samples (45.76 \%) (17). While in 2014, Al-Sayidi et al.(18), in Baghdad showed the rate of rotavirus infections was detected in $(91.3 \%)$ ).In neighboring countries studies on prevalence of Rota virus gastroenteritis was (40\%), (35\%)in Iran by Khaliliet al 2004 (19), and Turkey (37\%) by Karadag et al 2005 (20).

These different detection rates may be explained by different conditions of the studies, such as the season of sampling and the sampling methods. Rotavirus infection is also known as infantile diarrhea (since almost all children are infected in their first few years of life when they are especially at risk for the disease) or winter diarrhea. It is a highly contagious and unpredictable disease and may lead to severe dehydration and even death (21) However, prevalence of rotavirus disease varies from year to year because of the presence of other gastroenteritis-causing pathogens, differences in study outcomes and age strata can cause variation. Vaccine administration where effectiveness is greater than $80 \%(22)$.

Rotavirus infection occurred in all age groups between 1 month and 18 years with a peak in infants. There was a low rate of rotavirus isolation among the adults. This phenomenon may be attributed to the fact that the maternal antibodies are only protective in the first few months of infant life owing to their short half-life. As a result, this protection is lost as infants approach 6 months when the antibodies wane, hence the increase in the number of cases of rotavirus gastroenteritis as from 6 months (23). While, the increased frequency of rotavirus infection after two years of age may be attributed to the fact that most children may be 


\section{International Journal of Science and Research (IJSR) \\ ISSN (Online): 2319-7064}

Index Copernicus Value (2013): 6.14 | Impact Factor (2014): 5.611

associated with the dual condition of extremely high virus concentration in feces (more than 109 virus particles/g) and the low inoculums(10-100 virus particles) required for infection(24).

Males were tending to be more effected by RV in compares to females. Statistically, gender differences were nonsignificant $(p>0.05)$. These male predominate in the present study was in agreement with the results of some local studies $(25,26)$, and some regional neighboring countries $(27,28)$. Other study had found a relation between the risk of RV diarrhea and male gender in addition to other factors such as, poor education level (29).

Poor hygienic practices, home overcrowding, neglect, and lack of health education with poor health services. The high prevalence of RV demonstrated in children from rural areas can be related to the unsanitary practices associated with the child development. Socioeconomic status including level of mother education and residence was also studied as risk factor for transmission of Rotavirus. In a community-based survey carried out in two residential areas of different sanitary and socioeconomic conditions in Basra, Iraq, it was suggested that there is possibility of favoring Rotavirus transmission by poor personal hygiene, poor sanitation, and low educational level (30).

The prevalence of RV infection was least among infants who were breast fed and highest among infants on artificial formula, These findings are consistent with the findings of most other studies published worldwide (31) and this may be explained by the anti-infective and anti-inflammatory properties of human breast milk (32).

In our study, Rotavirus was isolated from the 15 out of 24 infants with respiratory tract infections. Respiratory mode of transmission had been suggested because of the association of human RV with respiratory signs and symptoms; although the causal relationship between respiratory and gastrointestinal symptoms had not been established as no RV particles had been isolated from respiratory secretions (33).

RV diarrhea children were significantly more likely to have dehydration and vomiting than non - RV diarrhea children. This indicated that RV diarrhea is a heavy burden in children health care, incurring great economic cost. Stephered et al (34) reported that vomiting was the initial symptom diarrheic children with RV gastroenteritis. Brabhan et al (35) had shown that RV is accompanied by abnormal gastric motor function, and this abnormality may be the cause of vomiting. Ruuska and Vesikari (36) recorded that most of children with RV were febrile, but only $14 \%$ had fever more than $39^{\circ} \mathrm{c}$.

In conclusion, the present study confirms the current burden of rotavirus in infants, and usually associated with one or more respiratory symptoms and it is highly prevalent among children from rural areas and of low mother education. The clinical features from children with rotavirus gastroenteritis are non-specific but highly suggestive and should raise the indexes of suspicion of infection with this virus.

\section{References}

[1] World Health Organization, 2005. World Health Report. Making Every Mother and Child Count. Geneva: World Health Organization.

[2] ElliottEJ. Acute Gastroenteritis in Children. British Medical Journal.2007; 334(7583): 35-40.

[3] Naghipour M, Nakgomi T. \& Nakagomi O. Issues with Reducing the Rotavirus Associated Mortality by Vaccination in Developing Countries.Vaccine. 2008; 26( 26): 3236-3241.

[4] Matthijnssens J, Otto PH, Ciarlet M, et al. VP6sequence-based cutoff values as a criterion for rotavirus species demarcation. Arch Virol. 2012; 157(6):11771182.

[5] Estes MK. \& Kapikian A. Rotaviruses. In: Knipe D, Griffin D, Lamb R, Martin M, Roizman B, Straus S, editors. Fields Virology Philadelphia, PA, USA: Wolters Kluwer Health; Lippincott, Williams and Wilkins; 2007. p. 1917.

[6] Kapikian A Z, Hoshino Y. \& Chanock RM. Rotaviruses, p. 1787-1833. In D. M. Knipe and P. M. Howley (ed.), Fields' virology, 4th ed. Lippincott Williams and Wilkins, Philadelphia 2001.

[7] Estes MK. Rotaviruses and their replication, p. 17471785. In D. M. Knipe and P. M. Howley (ed.), Fields virology. Lippencott-Raven Publishers, Philadelphia 2001.

[8] Antonella DD, Pierre RFK, Giovanni G,et al. Evaluation of rotavirus and intestinal parasite infection in a pediatric population in West Cameroon: Clinical characteristics and virus genotyping. African J. of Microbiology Res.2013; 7(35) :4473-4479.

[9] Grimwood K.\& Lambert SB.Rotavirus vaccines: opportunities and challenges. Hum Vaccin. 2009; 5(2):57-69.

[10] Parashar UD, Gibson CJ, Bresse JS, et al. Rotavirus and severe childhood diarrhea. Emerg Infect Dis. 2006; 12(2):304306.

[11] Junaidet $a l$. Incidence of rotavirus infection in children with gastroenteritis attending Jos University teaching hospital, Nigeria; Virology journal 2011; 8:233

[12] Hani OG, Khan A, Abdulwahab M, et al. Rotavirus Infection in Infants and Young Children in Makkah, Saudi Arabia; Jornal of medical association;(2005).

[13]Bos P, Kirsten M, Cronje RE, et al. Monitoring of rotavirus infection in a pediatric hospital by RNA electrophoresis. S. Afr. Med.J.1995; 85(9):887-91.

[14] Argüellles MH, Villegas GA, Costello A, et al. VP7 and VP8 genotyping of human group A rotavirus in Buenos Aires, Argentina. J. Clin. Microbiol. 2000; 38(1):252259.

[15] Tate JE, Panozzo CA, Payne DC,et al. Decline and change in seasonality of US rotavirus activity after the introduction of rotavirus vaccine. Pediatrics 2009; 465 471, 124:

[16] Buttery JP, Lambert SB, Grimwood K, et al: Reduction in rotavirus-associated acute gastroenteritis following introduction of rotavirus vaccine into Australia's National Childhood vaccine schedule. Pediatr Infect Dis J 2011; S25-S29, 30

[17]AL- Khafaji YA. \& AL-Jiboury HJ. Detection of Rotavirus in diarrhea stool samples of children with 


\section{International Journal of Science and Research (IJSR) \\ ISSN (Online): 2319-7064}

Index Copernicus Value (2013): 6.14 | Impact Factor (2014): 5.611

acute gastroenteritis in Babylongovernorate, Iraq International Research Journal of Microbiology 2013; 4(3) : 84-88.

[18] Al-Sayidi RHE, Fadhil HY. \& AL- Hamdani FG. Rapid Diagnosis of Rota-Adenoviruses for Acute Gastroenteritis in hospitalized Children under 4 Years Old, Baghdad. Int. J. Curr. Microbiol. App. Sci. 2014; 3(1): 453-458

[19] Khalili B, Cuevas LE, Reisi N, et al Epidemiology of rotavirus diarrhoea in Iranian children. J Med Virol. 2004; 73:309-12.

[20] Karadag A, Acikgoz ZC, Avci Z, et al. Childhood diarrhea in Ankara, Turkey: epidemiological and clinical features of rotavirus-positive versus rotavirus negative cases. Scand J Infect Dis. 2005; 37:269-75.

[21] Khoury, et al. Burden of rotavirusgastroenteritis in the Middle Eastern and North African pediatric population. BMC Infectious Diseases 2011; 11:9

[22] Patel MM, Glass R, Desai R, Fulfilling the promise of rotavirus vaccines: how far have we come since licensure, Lancet Infectious Diseases, 2012; 12(7): 561570.

[23] Patel M, Shane AL, Parashar UD, et al. Oral Rotavirus Vaccines: How Well Will They Work Where They Are Needed Most? The Journal of Infectious Diseases. 2009; 200:S39-S48.

[24] Grassi T, Bagordo F, Idolo A, et al. Rotavirus detection in environmental water samples by tangential flow ultrafiltration and RT-nested PCR. Journal of Environmental Monitoring and Assessment.2009; 10:1661-1669.

[25] Al-Jabiry AJ. Prevalence of rotavirus infection among children with acute gastroenteritis in Thi-Qar Governorate, Thi-Qar med. J.2009; 3(1): 88-100.

[26] Ali GI, Abdullah HI. \& Younis HM. Rotavirus infection in children suffering from gastroenteritis in Kirkuk province, Tikrit J. of pure sci.2010; 15(1): 175-179.

[27] Kargar M, Zare M. \& Najafi A. Molecular epidemiology of rotavirus strains circulating among children with gastroenteritis in Iran, Iranian $\mathrm{j}$. of pediat.2012; 22(1): 63-69.

[28] Al-Musawi M, Zainaldeen H, Shafi F, et al. Rotavirus gastroenteritis in children under 5 years in the kingdom of Bahrian: hospital- based surveillance. Clinic Epidem.2013; 5: 269-275.

[29] Albano F, Bruzzese E, Bella A, et al. Rotavirus and not age determines gastroenteritis severity in children: a hospital-based study. Eur. J. Pediatr. 2007; 166(3):241 247.

[30]Al Kerwi AA, Al-Samaria AG. \& Yacoub AA. Rotavirus infection among children under the age of five in Basra: a community based survey, WHO. 1993; 7: $41-47$.

[31] Clemens J, Rao N, Eng M, et al. Breast feeding and the risk of life threatening rotavirus diarrhea. J Paed.1993; 92:680-5.

[32]Chierici R. Antimicrobial action of lactoferrin.Adv.Nutr.Res.2001; 10:247-49.

[33] Jian Zheng B, Xu Chang R, Zhang Ma G, et al. Rotavirus infection of the oropharynx and respiratory tract in young children, Journal of Medical Virology. 1991; 34(1): 29-37.
[34] Stephered RW. A clinical study of Rotavirus like agent infection .Lancet. 1995; (2):1082.

[35] Brabhan PK, Salam MA. \& A.M. Gastric emptying of liquid in children suffering from acute rotaviral gastroenteritis. Gut.1992; (33):26.

[36] Ruuska T. \& Vesikari T. Rotavirus disease in finish children: use of numerical scores for clinical severity of diarrhea episodes .Scand.J.Infect.Dis.1990; (22):259. 